\title{
Does Copay Amount or Insurance Type Impact the Duration of Levonorgestrel IUD Retention?
}

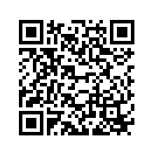

\author{
Lauren E Vestal ${ }^{1}$, Mistie P Mills ${ }^{2}$ and Erma Z Drobnis ${ }^{2 *}$ \\ ${ }^{1}$ Department of Obstetrics, Gynecology and Women's Health, University of Missouri-Kansas City School of Medicine, USA \\ ${ }^{2}$ Department of Obstetrics, Gynecology and Women's Health, University of Missouri-Columbia School of Medicine, USA
}

Submission: February 09, 2019; Published: February 21, 2019

*Corresponding author: Erma Z Drobnis, Department of Ob/Gyn \& Women's Health, University of Missouri, USA

\begin{abstract}
Objective: To determine whether co-payment amount or insurance status at the time of levonorgestrel-releasing intrauterine device (Mirena IUD) insertion affects duration of device retention.

Study design: Insertions and removals of levonorgestrel-releasing IUDs performed at an academic Obstetrics and Gynecology practice from October 2004 to October 2009. Data collection was performed, via procedure codes and chart review, yielding 199 IUD insertions for 160 patients, with 161 cases of individual IUD insertion-removals and 38 re-insertions with the IUD retained at study completion. The median (interquartile range) retention duration was \& 10 (4.4-20) months, copay amount \$3.5 (\$0-25), patient age 26 (23-32) years, number of prior pregnancies 2 (1$3)$, number of prior abortions $0(0-1)$ and number of living children 2 (1-2). The primary outcome was IUD retention duration in relation to copay amount at insertion. Data analysis for 161 IUD insertions with removals was performed using Mann-Whitney rank sum analysis and Spearman correlation, and for the entire study cohort of 199 IUD insertions, Kaplan-Meier log-rank and multivariable Cox hazard analyses, right-censored for IUDs retained at study completion.
\end{abstract}

Results: Retention time was not related to patient cost at time of insertion nor to privately-funded insurance. Factors that independently decreased IUD retention time were insertion for reason other than contraception (duration of 3 vs. 11 months; risk ratio 2.9; 95\% confidence interval 1.5-5.4) and removal after second IUD insertion during study interval (10 vs. 11 months; 3.3; 1.7-6.1).

Conclusion: Copay amount and insurance type may not relate to duration of levonorgestrel-releasing IUD retention.

\section{Introduction}

With the number of unintended pregnancies in the United States reaching almost three million in 2011 [1] and with the escalating debate over controlling health care costs, aiding patients in choosing cost-effective and reliable contraception is paramount. Currently, $45 \%$ of pregnancies in the United States annually are unintended, and approximately $5 \%$ of reproductiveage women have an unintended pregnancy each year [1,2]. By age 45 years, over half of women in the United States have had an unintended pregnancy and 3 in 10 will have had an abortion. These numbers remain significantly higher than those in numerous other developed countries.

As conversation and legislative discussions continue regarding federal funding of contraception and of pregnancy care, it is essential to note that the total public expenses of unintended pregnancies nationwide were estimated at $\$ 21$ billion in 2010 [1]. Of that, $\$ 14.6$ billion were federal expenditures and $\$ 6.4$ billion were state expenditures. With appropriate counseling and contraceptive guidance, it may be possible to decrease these costs.

The women at greatest risk of unintended pregnancy are those that use contraception inconsistently or incorrectly and those that do not practice any form of contraception. They account for $41 \%$ and $54 \%$, respectively, of all unintended pregnancies in the United States [1]. If these women receive counseling and highly effective contraception [3], the numbers of unintended pregnancy will decline, as shown in the Contraceptive CHOICE study [4].

The 52mg levonorgestrel-releasing intrauterine device (Mirena IUD) has been FDA-approved for contraception since 2000 , and is approved for usage up to five years. This progestinreleasing IUD (pIUD) is one of the most effective contraceptive agents [5-10]. In addition, recent research into cost-effectiveness of contraception in the US has revealed that the pIUD is also one of the most cost-effective methods currently available [7-12]. 
The cost-effectiveness of the pIUD has been well-documented if the device is retained for the full five years [7-10]. Importantly, the cost-effectiveness can be drastically affected if not retained for its intended duration. Considerable data exist investigating contraceptive choice as it relates to race, age, socioeconomic status, parity and marital status [9]; however, no research addresses the use of the pIUD specifically as it relates to insurance provider or copay and its relation to retention. If a difference in retention duration is found to be related to these factors, counseling could maximize pIUD usage which may decrease healthcare financial strain.

With recent changes in government coverage of contraceptive care [13], more women have access to contraception. It is therefore important to investigate whether the woman's payer status relates to her retention of highly effective contraception.

\section{Materials and Methods}

This retrospective chart review was approved by the University of Missouri Health Sciences Institutional Review Board. Using American Medical Association Current Procedural Terminology (CPT) procedure codes, records of all insertions and removals of Mirena pIUDs performed at the University of Missouri-based Obstetrics and Gynecology practice were collected during the period of October 2004 to October 2009. Data collection was performed by direct chart review by one reviewer (LV). Data were matched for those patients with insertion and removal for this time frame. For these patients, data collected included type of insurance provider, insurance company, copay requirements and length of pIUD retention. Some patients had a pIUD removed followed by re-insertion of a new pIUD, and these second pIUD insertions were included in right-censored analyses.

Inclusion criteria were as follows: At least one levonorgestrelreleasing IUD placed and removed during the study period by the University-based Obstetrics and Gynecology practice. Exclusion criteria were as follows: lack of documentation and inaccurate procedure coding.

The primary outcome variable was the retention time for pIUD in relation to up front patient cost at the insertion visit. Patient cost was categorized into 4 groups: $\$ 0$ for no copay; $<\$ 50$ and $\$ 50$ - $\$ 100$ for insured patients with a copay; and $\$ 15,000$, which was the cost of the pIUD for patients with no insurance coverage. Secondary outcome variables were age, number of prior pregnancies, number of term pregnancies, number of prior abortions, number of living children, delivery within the past 12 months, whether the patient had a second pIUD insertion within the study period, contraception as the indication for insertion, and whether the pIUD was removed for desire to become pregnant.

Because retention time was not normally distributed, MannWhitney rank sum analyses and Kruskal-Wallis ANOVA were used to compare pIUD retention for categorical factors, and Spearman rank sum correlation for numerical outcomes when pIUD insertion was followed by removal during the study period. In analyses of all pIUD insertions, including those retained at study completion, Kaplan-Meier analyses were used for univariable analyses while multivariable, Cox regression analyses were used to determine how the "risk" of pIUD removal over time for the factors studied. Hazard analyses were right-censored to account for women retaining an pIUD at the end of the study.

\section{Results}

Table 1: Descriptive statistics for 199 pIUD insertions for 160 patients.

\begin{tabular}{|c|c|}
\hline Categorical Variable & \% Yes \\
\hline Copay $=\$ 0$ & 42 \\
\hline Copay $<\$ 50$ & 43 \\
\hline Copay $\$ 50-\$ 100$ & 9 \\
\hline Copay $=\$ 1500$ & 57 \\
\hline Payer Source: Private Insurance & 40 \\
\hline Payer Source: Government-Funded Insurance & 3 \\
\hline Payer Source: Self-Pay & 20 \\
\hline Second pIUD insertion during study period & 93 \\
\hline pIUD inserted for contraception & 58 \\
\hline Delivery in the 12 months before insertion & 94 \\
\hline Prior pregnancy before insertion & 39 \\
\hline Prior abortion before insertion & 93 \\
\hline Presence of living children & 23 \\
\hline Removal in order to become pregnant & 23 \\
\hline Removed in order to become pregnant? & \\
\hline
\end{tabular}

\begin{tabular}{|c|c|c|c|}
\hline Numerical Variable & Median & $\begin{array}{c}\text { Interquartile } \\
\text { Range }\end{array}$ & Range \\
\hline Copay amount (\$) & $\$ 3.50$ & $0-25$ & $0-1500$ \\
\hline $\begin{array}{c}\text { Duration of pIUD retention } \\
\text { (months)* }\end{array}$ & 10 & $4.4-20$ & $0.03-59$ \\
\hline Age at pIUD insertion (years) & 26 & $23-32$ & $15-50$ \\
\hline Prior pregnancies & 2 & $1-3$ & $0-8$ \\
\hline Prior abortions & 0 & $0-1$ & $0-5$ \\
\hline Prior term pregnancies & 2 & $1-2$ & $0-8$ \\
\hline Presence of living children & 2 & $1-2$ & $0-8$ \\
\hline Living children & 2 & $1-2$ & $0-8$ \\
\hline
\end{tabular}

*161 with insertion and removal

Data collection yielded 1,830 pIUD insertion and removal events during the study period. After sorting for individual patients with at least 1 insertion and 1 removal event, 205 pIUD insertions remained. Exclusions were 3 for inaccurate coding and 3 due to inability to obtain data from the electronic medical record or paper chart. This yielded 199 pIUD insertions in 160 patients. The patient demographics and descriptive statistics for the pIUD insertions are shown in Table 1. Of the pIUD insertions studied, 161 individual pIUDs were inserted then removed during the study period. Thirty-eight pIUDs were not removed, 28 were second pIUDs placed in patients with a prior insertion/ 
removal and 10 were placed when the first pIUD was removed due to expiration of its 5 year effective lifespan. We assumed that these pIUDs were in place at the end of the study.

Table 2: Median pIUD retention duration for 161 pIUD insertions with removal during the study period, evaluated for categorical factors.

\begin{tabular}{|c|c|c|c|}
\hline Variable & No & Yes & $\mathbf{p}^{*}$ \\
\hline $\begin{array}{c}\text { Second pIUD insertion } \\
\text { during study period }\end{array}$ & 10 & 11 & 0.75 \\
\hline $\begin{array}{c}\text { pIUD inserted for } \\
\text { contraception }\end{array}$ & 3 & 11 & $0.0025^{*}$ \\
\hline $\begin{array}{c}\text { Delivery in the } 12 \text { months } \\
\text { before insertion }\end{array}$ & 7 & 15 & $0.000008^{*}$ \\
\hline $\begin{array}{c}\text { Prior abortion before } \\
\text { insertion }\end{array}$ & 10 & 9 & 0.32 \\
\hline $\begin{array}{c}\text { Removal in order to become } \\
\text { pregnant }\end{array}$ & 8 & 16 & $0.00056^{*}$ \\
\hline
\end{tabular}

* $p$ values from univariable Mann-Whitney rank sum tests

Table 3: Relationship between Duration of pIUD retention and numerical factors for 161 pIUD insertions with removal during the study period.

\begin{tabular}{|c|c|c|c|c|c|}
\hline \multirow{2}{*}{$\begin{array}{c}\text { Payer } \\
\text { Source }\end{array}$} & $\begin{array}{c}\text { Private } \\
\text { Insurance }\end{array}$ & $\begin{array}{c}\text { Government- } \\
\text { Funded } \\
\text { Insurance }\end{array}$ & Self-Pay & \multicolumn{2}{|c|}{$\mathbf{p}^{*}$} \\
\cline { 2 - 6 } & 9 & 12 & 12 & \multicolumn{2}{|c|}{0.51} \\
\hline \multirow{2}{*}{$\begin{array}{c}\text { Copay } \\
\text { Amount }\end{array}$} & $\$ 0$ & $<\$ 50$ & $\$ 50-\$ 100$ & $\$ 1500$ & $\mathrm{p}^{*}$ \\
\cline { 2 - 6 } & 11 & 11 & 9 & 8 & 0.47 \\
\hline
\end{tabular}

* $p$ values from univariable Mann-Whitney rank sum tests

Table 4: Risk analysis of short pIUD retention duration for 199 pIUD insertions during the study period.

\begin{tabular}{|c|c|c|c|c|}
\hline \multicolumn{2}{|c|}{ Variable } & Risk Ratio & $95 \% \mathrm{CI}$ & $\mathbf{P}$ \\
\hline \multicolumn{2}{|c|}{ Copay Amount } & 1.0 & $\begin{array}{c}0.9995- \\
1.0006\end{array}$ & 0.80 \\
\hline \multirow{2}{*}{ Payer Source } & $\begin{array}{l}\text { Private vs } \\
\text { Self-Pay }\end{array}$ & 1.01 & $0.34-3.0$ & 0.98 \\
\hline & $\begin{array}{l}\text { Government } \\
\text { vs Self-Pay }\end{array}$ & 0.96 & $0.31-3.0$ & 0.94 \\
\hline \multicolumn{2}{|c|}{$\begin{array}{l}\text { Second pIUD insertion during } \\
\text { study period }\end{array}$} & 3.3 & $1.7-6.1$ & $0.0003^{*}$ \\
\hline \multicolumn{2}{|c|}{ pIUD inserted for contraception } & 2.9 & $1.5-5.4$ & $0.0011 *$ \\
\hline \multicolumn{2}{|c|}{$\begin{array}{l}\text { Delivery in the } 12 \text { months } \\
\text { before insertion }\end{array}$} & 1.2 & $0.79-1.9$ & 0.37 \\
\hline \multicolumn{2}{|c|}{ Prior abortion before insertion } & 0.73 & $\begin{array}{c}0.51- \\
1.03\end{array}$ & 0.069 \\
\hline \multicolumn{2}{|c|}{ Number of living children } & 0.67 & $0.35-1.3$ & 0.24 \\
\hline \multicolumn{2}{|c|}{$\begin{array}{l}\text { Removal in order to become } \\
\text { pregnant }\end{array}$} & 1.1 & $0.76-1.7$ & .50 \\
\hline \multicolumn{2}{|c|}{ Age at pIUD insertion } & 0.99 & $\begin{array}{c}0.97- \\
1.02\end{array}$ & 0.69 \\
\hline
\end{tabular}

* $p$ values from multivariable Cox log-rank regression analysis

First, we looked at the 161 pIUD insertions that were followed by removal during the study period. pIUD retention time was not related to copay category $(\$ 0,<\$ 100, \$ 1500)$, or to payer category (private insurance, government payer, or self-pay), by univariable analysis of these factors (Table 2). Multivariable risk analysis of the entire population also found no difference in duration of pIUD retention for copay or payer categories when controlling for the other factors analyzed (Table 3\&4).

Univariable analysis (Tables 1\&2) found that pIUD retention duration was longer if the pIUD was inserted for contraception, if the patient had delivered within 12 months before pIUD insertion, if the pIUD was removed in order to attempt pregnancy, or if the patient was younger at the time of pIUD insertion. Factors not associated to retention duration were whether the pIUD insertion was the second for the same patient, if the patient had one or more abortions prior to pIUD insertion, the number of pregnancies or term pregnancies prior to pIUD insertion, or the number of living children at the time of insertion. When controlling for other factors in a multivariable model, whether the pIUD insertion was the second for the same patient became a significant factor and if the pIUD was inserted for contraception remained significant, while all other factors were not related to pIUD retention duration. The 15 pIUD insertions not performed for contraception were 13 for menorrhagia, 1 for endometriosis and 1 for endometrial hyperplasia.

\section{Discussion}

In this unique study, we have demonstrated that retention of pIUDs is not affected by financial motivators. Neither cost to patient nor payer categories affected duration of pIUD retention in our study. Retention duration was shorter for second pIUD insertions during the study period, which is not unexpected. Longer retention duration was also found if the pIUD was inserted for contraception, compared with those placed for other medical indications.

As discussed, very few analyses have investigated these variables specifically related to retention of pIUDs, thus this study is novel. Several studies have investigated the likelihood of women to use medically prescribed contraception depending on their personal cost. In a large, recent study, Carlin et al. [14] compared contraceptive choice in a cohort of women with employer-sponsored coverage, before and after the Affordable Care Act (ACA)-mandated decrease in cost-sharing (i.e. lower cost to patient). There was an increase in women's use of prescribed contraception after ACA compliance compared with before. These authors also noted a $2.3 \%$ increase over the $30 \%$ of women who selected long term contraception methods. This suggests that women with insurance through work are more likely to use prescribed contraception methods if their outof-pocket cost is low. Consistent with this finding, two earlier studies $[15,16]$ found that IUD initiation rates were less for those women with employer-sponsored or private insurance plans requiring higher cost sharing than those who had less outof-pocket cost. Limitations to these studies were they did not address the factors effecting retention or continuation of long term contraception. 
Considering the current political climate, with fluctuating legislation affecting contraception and women's health care, it is very important to know what motivates patients' long term decisions. This study showed that the up-front cost of reliable, long-acting reversible contraception did not significantly affect a woman's decision regarding length of usage in our population. This information is valuable when counseling women on their reproductive plans. As cost does not appear to relate to patients' contraceptive length of use, physicians can be confident in recommending long-acting reversible contraceptives such as the pIUD to all patient populations. Furthermore, legislators should be assured that by reducing fees and increasing access, they will not hamper the retention of long-acting reversible contraceptives like the pIUD. Appropriate counseling, together with legislation to increase access, can decrease health care expenditures by decreasing the rate of unplanned pregnancy.

Our study was limited in that it may have been underpowered to detect differences. The possibility of the latter is less likely because the risk ratio of pIUD removal by up-front cost was essentially 1.0 with tight $95 \%$ confidence interval. Other limitations of this study include its retrospective nature as well as the timeframe occurring prior to the implementation of the ACA. Furthermore, whether this data is generalizable is uncertain, as this was a single-site study.

A strength of the study is that the data were collected by a single reviewer, thus limiting errors and imprecision. Additionally, to our knowledge this is the first study of its kind, investigating financial motivators as related to pIUD retention. Even though this study was conducted prior to the implementation of the ACA, it may be more useful, as the data is unaffected by those changes. Opportunities for more research exist. They include the analysis of other data points from this study, how the ACA has affected retention time, whether retention is dependent on type of IUD and investigating these data points at multiple sites for more generalizability.

\section{Implications}

This is the first study of its kind in the US to investigate IUD retention duration as related to patient cost/insurance type at the time of insertion. This can have major implications for counseling and access to IUDs given the current legislative climate.
A

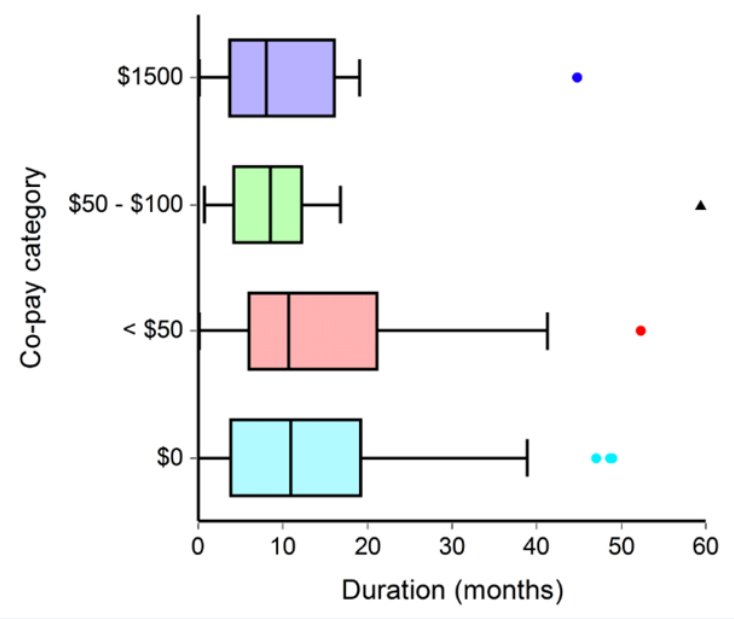

Figure 1A

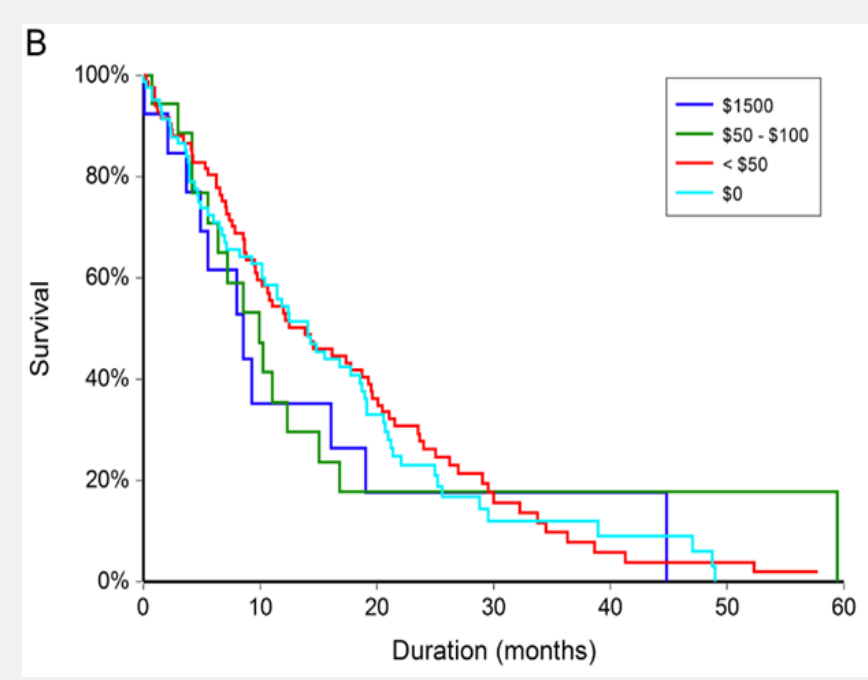

Figure 1B

\section{Figure 1: Retention time for pIUD in relation to the co- payment required at time of insertion}

All pIUD insertions that resulted in removal during a 5 year study period at a single university-based Obstetrics and Gynecology practice were included $(n=161)$. A. pIUD retention duration, categorized by patient cost at the time of insertion, is shown using Tukey box plots with filled triangles indicating outliers + 3.0 times the interquartile range from the median. B. Kaplan-Meier curves from right-censored survival analysis (pIUD retention duration) of all pIUD insertions during the study period $(n=199)$ categorized by copay category detected no difference between copay groups ( $\mathrm{p}=0.90$ by log-rank analysis).

\section{Figure 2: Retention time for pIUD in relation to whether patients had private insurance or not}

All patients who had a pIUD inserted and removed within the 5 year study period at a single university-based Obstetrics and Gynecology practice were included ( $\mathrm{n}=167)$. A. Box plots showing data for patients with and without private insurance. Horizontal lines on the box plots enclose $90 \%$ of the data. B. Kaplan-Meier curves from right-censored survival analysis (pIUD retention duration) of all pIUD insertions during the study period ( $\mathrm{n}=199$ ) categorized by payer category detected no difference between copay groups ( $\mathrm{p}=0.26$ by log-rank analysis). 


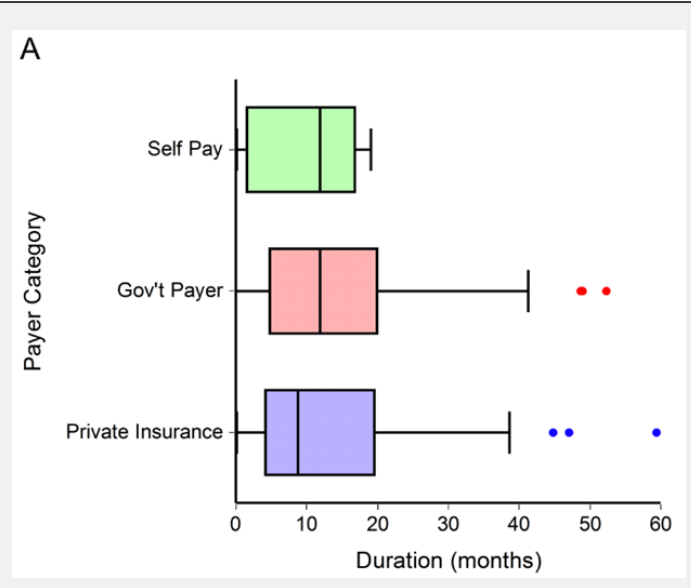

Figure 2A

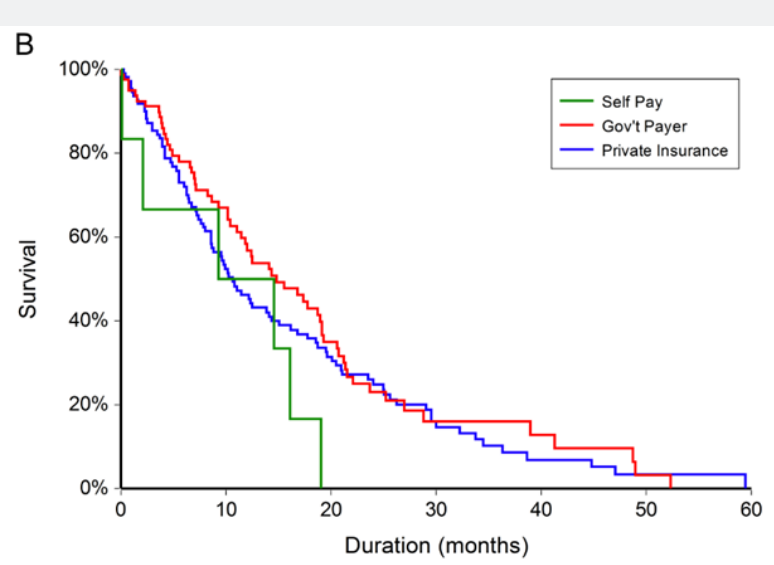

Figure 2B

\section{References}

1. Guttmacher Institute (2015) Unintended Pregnancy in the United States. Guttmacher, pp. 1-4

2. Finer LB, Zolna MR (2011) Unintended pregnancy in the United States: Incidence and disparities, 2006. Contraception 84(5): 478-485.

3. American College of Obstetricians and Gynecologists (2016) Committee Opinion No. 654 Summary: Reproductive Life Planning to Reduce Unintended Pregnancy. Obstet Gynecol 127(2): 415.

4. Secura GM, Allsworth JE, Madden T, Mullersman JL, Peipert JF, et al. (2010) The Contraceptive CHOICE Project: Reducing barriers to longacting reversible contraception. Am J Obstet Gynecol 203(2): 115.

5. French R, Cowen F, Mansour D, Higgins J, Robinson A, et al. (2000) Levonorgestrel-releasing intrauterine systems (Mirena) compared with other methods of reversible contraceptives. BJOG 107(10): 12181225 .

6. Bayer (2015) Mirena IUD Prescribing Information. Online pp. 1-27.

7. Backman T (2004) Benefit-risk assessment of the levonorgestrel intrauterine system in contraception. Drug Saf 27(15): 1185-1204.

8. Phillips CJ (2000) Economic Analysis of Long Term Reversible Contraceptives: Focus on Implanon (R). Pharmacoeconomics 17(2): 209-221.

9. Mosher WD, Martinez GM, Chandra A, Abma JC, Willson SJ, et al. (2004) Use of contraception and use of family planning services in the United States: 1982-2002. Adv Data 350: 1-36.

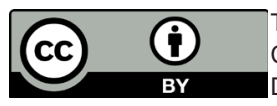

This work is licensed under Creative Commons Attribution 4.0 License DOI: 10.19080/JGWH.2019.14.555884
10. Mavranezouli I (2009) LARC Guideline Development Group. The cost-effectiveness of long-acting reversible contraceptive methods in the UK: analysis based on a decision-analytic model developed for a National Institute for Health and Clinical Excellence (NICE) clinical practice guideline. Hum Reprod 23: 1338-1345.

11. Foster DG, Rostovtseva DP, Brindis CD, Biggs MA, Hulett D, et al. (2009) Cost savings from the provision of specific methods of contraception in a publicly funded program. Am J Public Health 99(3): 446-451.

12. Trussell J, Lalla AM, Doan QV, Reyes E, Pinto L, et al. (2008) Cost effectiveness of contraceptives in the United States. Contraception $79(1): 5-14$

13. Politi M, Sonfield A, Madden T (2016) Addressing Challenges to Implementation of the Contraceptive Coverage Guarantee of the Affordable Care Act. JAMA 315(7): 653-654.

14. Carlin CS, Fertig AR, Dowd BE (2016) Affordable care act's mandate eliminating contraceptive cost sharing influenced choices of women with employer coverage. Health Affairs 35(9): 1608-1615.

15. Pace LE, Dusetzina SB, Fendrick AM, Keating NL, Dalton VK, et al. (2013) The impact of out-of-pocket costs on the use of intrauterine contraception among women with employer-sponsored insurance. Med Care 51(11): 959-963.

16. Gariepy AM, Simon EJ, Patel DA, Creinin MD, Schwarz EB, et al. (2011) The impact of out-of-pocket expense on IUD utilization among women with private insurance. Contraception 84(6): e39-e42.

\section{Your next submission with Juniper Publishers will reach you the below assets}

- Quality Editorial service

- Swift Peer Review

- Reprints availability

- E-prints Service

- Manuscript Podcast for convenient understanding

- Global attainment for your research

- Manuscript accessibility in different formats ( Pdf, E-pub, Full Text, Audio)

- Unceasing customer service

Track the below URL for one-step submission https://juniperpublishers.com/online-submission.php 